\title{
Understanding Presence, Affordance and the Time/Space Dimensions for Language Learning in Virtual Worlds
}

\author{
Susanna Nocchi \\ Technological University Dublin, susanna.nocchi@tudublin.ie \\ Françoise Blin \\ Dublin City University
}

Follow this and additional works at: https://arrow.tudublin.ie/aaschlanart

Part of the Education Commons, Italian Language and Literature Commons, and the Modern Languages Commons

\section{Recommended Citation}

Nocchi, S., Blin, : Understanding Presence, Affordance and the Time/Space Dimensions for Language Learning in Virtual Worlds, EuroCALL 2013 Proceedings. In L. Bradley \& S. Thouësny (Eds.), 20 Years of EUROCALL: Learning from the Past, Looking to the Future. Proceedings of the 2013 EUROCALL Conference, Évora, Portugal (pp. 1-6). doi:10.14705/rpnet.2013.000159

This Article is brought to you for free and open access by the Languages at ARROW@TU Dublin. It has been accepted for inclusion in Articles by an authorized administrator of ARROW@TU Dublin. For more information, please contact arrow.admin@tudublin.ie, aisling.coyne@tudublin.ie,gerard.connolly@tudublin.ie.

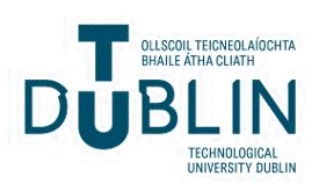




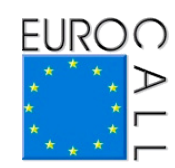

\title{
Understanding Presence, Affordance and the Time/Space Dimensions for Language Learning in Virtual Worlds
}

\author{
Susanna Nocchi ${ }^{1}$ and Françoise Blin ${ }^{2}$
}

\begin{abstract}
Notwithstanding their potential for novel approaches to language teaching and learning, Virtual Worlds (VWs) present numerous technological and pedagogical challenges that require new paradigms if the language learning experience and outcomes are to be successful. In this presentation, we argue that the notions of presence and affordance, together with the time/space dimensions of interactions in virtual worlds (e.g. Bakhtin's (1981) chronotope, Foucault's (1984) heteropia, and Lemke's (2000) heterochrony), provide new insights into language learners' trajectories as they attempt to carry out tasks that are designed to make use of virtual worlds' characteristics and potentialities. We explore and analyse a critical incident that occurred during the realisation of a language learning task by university learners of Italian in Second Life $\mathbb{C}$. Recordings of the session, teacher observations, learner reflections and interviews have provided large amounts of data highlighting a number of critical incidents that emerged during their execution. Analysing these critical incidents through the lenses of presence, affordance, and time/space inseparability allows us to highlight the non-linearity of temporal and spatial aspects of interactions in virtual worlds, and to reveal the emergence of affordances and learning chronotopes linked to such interactions. In turn, the analysis of these emerging learning chronotopes helps us refine the design and implementation of language learning tasks in virtual worlds.
\end{abstract}

Keywords: language learning, virtual worlds, affordances, learning chronotopes.

1. Dublin Institute of Technology, Dublin, Ireland; susanna.nocchi@dit.ie

2. Dublin City University, Dublin, Ireland

How to cite this article: Nocchi, S., \& Blin, F. (2013). Understanding Presence, Affordance and the Time/Space Dimensions for Language Learning in Virtual Worlds. In L. Bradley \& S. Thouësny (Eds.), 20 Years of EUROCALL: Learning from the Past, Looking to the Future. Proceedings of the 2013 EUROCALL Conference, Evora, Portugal (pp. 1-6). Dublin/Voillans: (C) Research-publishing.net. 


\section{Introduction}

In the last decade VWs have been used and studied by the educational community, with a particular focus on their potential for immersive learning, simulation and cross-cultural exchanges. Language learning has become a popular activity in VWs (see experiences, such as Avalon, Euroversity,Virtlantis), and the enthusiasm of the foreign language (FL) teaching community has led many to tap into the potentialities offered by VWs such as Second LifeC.

Research in the pedagogy of FL teaching and learning in VWs is however still quite young and an analysis of some of the first language courses in these environments showed that early adopters tended to reproduce known and safe pedagogical choices; this brought the researchers' attention on how to best exploit the unique characteristics of this new technology (Blin, Nocchi, \& Fowley, 2013; Girvan \& Savage, 2010; Zheng, 2012; Zheng \& Newgarden, 2011).

In this short paper, we show how the concepts of presence and affordance, as well as the spatial and temporal dimensions of VWs can be useful tools for making sense of these spaces as learning environments.

\subsection{Presence and affordances}

The cyber psychologist Riva defines presence in a mediated environment as "the intuitive perception of successfully transforming intentions into action" (Riva, Waterworth, Waterworth, \& Mantovani, 2011, p. 2) and social presence as "the capacity to act on one's intentions and to understand the intentions of the others" (Riva, 2004, p. 51). According to Riva (2004), a high degree of presence can give an indication of how successful one has been in using the medium; through full usability of the medium one can act how one wants and become more fully aware of the medium's possibilities for action, i.e. its affordances (Kaptelinin \& Nardi, 2012). Our understanding of affordances draws on an activity theoretical perspective, which highlights the strong link between affordance, context, activity, the user's previous history and experience and the mediational aspect of the technological tool/artefact and its cultural and historical significance for the user and the educational activity (Morgan, 2007).

\subsection{Spatial and temporal dimensions - heterotopia and the chronotope}

VWs do not only provide a new learning environment with exciting affordances; a VW is a separate space, but it is also part of the user's physical world. Foucault's 
(1967) concept of heterotopia as a space that is in relation to other sites but, at the same time, contains in a single place different spaces and locations that can be incompatible with each other, seems apt to describe the cyber experience. Heterotopias "always presuppose a system of opening and closing that both isolates them and makes them penetrable at one at the same time" (Foucault, 1967, p. 7). VWs, as well, are located in the world and outside it and assemble a variety of real and imagined spaces and realities.

Time is also an interesting dimension of the cyber reality. When we are immersed in a VW's historical period, season and time, we are also still living and acting in our own real time, whose reality intersects with the VW reality. Bakhtin's (1981) concept of chronotope, a "connectedness of temporal and spatial relationships [...] in literature" (Bakhtin, 1981, p. 84), can be usefully utilised to observe how time is conceptualised in a learning space and in computer-assisted collaboration (Ligorio \& Ritella, 2010).

\section{Method}

SLitaliano was an Italian language course that took place in Second Life(C) in 2011/2012. The course was designed for International Business and Languages students at the Dublin Institute of Technology, who wanted to work on their Italian language and intercultural competence, in view of spending their Erasmus year in an Italian university. SLitaliano consisted of 9 in-world sessions. Each session was preceded by pre-session tasks on the course wiki.

\subsection{Si Mangia! (Let's eat!)}

Session 4 of SLitaliano was called "Si mangia!" (Let's eat) and focused on Italian food, food habits and food culture. The session took place on Imparafacile Island, and most of it was spent in an Italian restaurant/pizzeria. The participating students, Bea, Ita and Dub, had met a group of Italian native speakers outside the restaurant and had already tackled a language task with their help.

At this point in the session, students and Italians are facing a table covered with food and kitchen tools and have been asked to devise a recipe using the objects and ingredients they see on the table. These scripted objects show lexical and morphological information about them if the users hover their mouse over them. As part of their wiki pre-session tasks, students had been asked to make sure their hover tips were active. 


\subsection{Data collection and analysis}

The session was recorded and multimodal interactions were transcribed for subsequent analysis. Focus shifts were identified, which defined episodes that were then analysed. Such focus shifts were primarily triggered by technical issues or breakdowns, and lexical or intercultural queries. Some were expected, others emerged as students set out to complete the tasks assigned to them.

The episode discussed in this article was the result of an unexpected technical issue that affected the flow of the activity and caused a shift in the focus of the action.

\section{Results}

Before starting to devise a recipe, the students needed to properly identify the objects they were to use, by zooming in on them and/or hovering their mouse over them to get lexical and grammatical information if needed. Two students, Bea and Dub, had not activated their hover tips as instructed. As a result, they could not take advantage of the affordances provided by the hover tips and by the zooming option.

As they were unable to access information on the objects on the table, the group momentarily left the simulation to create an alternative solution that would enable students to complete the task. Ita was given the role of the 'seer' for the group and helped her colleagues find the names of the objects they could not recognise. Also, the Italians left their spectator role and actively helped the students in Local Chat, providing technical and lexical tips.

The group had to resort to alternative actions which caused the emergence of various affordance based actions. The actions connected to this episode were: languaging in local and voice chat, native speaker support in local and voice chat, technical support in voice chat, language reflection, and target language input in local chat.

Also, the 'hover tips' incident brought about extensive language production from the students, with a total of 51 exchanges in Voice Chat and 3 in Local Chat (Bea: 7 instances; Dub: 18 instances; Ita: 29 instances).

As illustrated in Figure 1 below, the technical issue caused a shift in the focus of attention of the group while giving rise to the emergence of a new chronotope and of different affordances. 
Figure 1. Hover tips episode triggering a focus shift as well as a temporal and spatial one

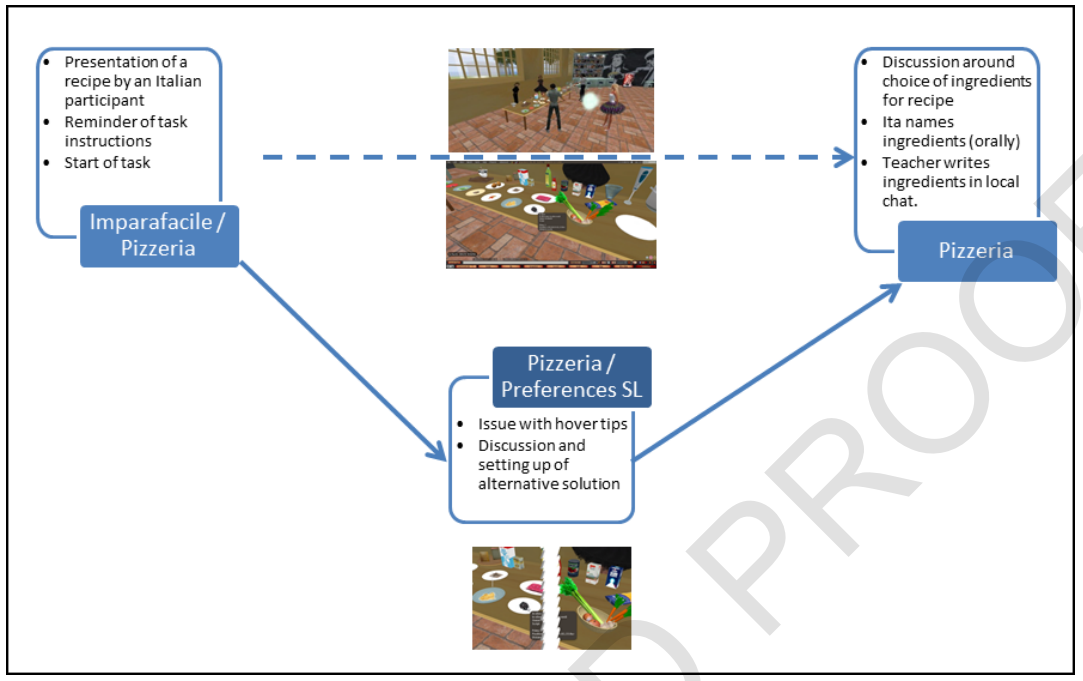

\section{Discussion and conclusions}

The hover tips incident illustrates the breakdowns and repairs that are likely to occur in a virtual world. Such episodes enable us to better understand the relationship between affordance, presence, and the spatio-temporal aspects that are characteristic of "in-world" interactions. The learning environment briefly described above provided educational, technological, and linguistic affordances to students. While some of these affordances were enacted, others were not. As Bea and Dub were not in a position to realise the technological affordances offered by Second Life $\mathrm{C}$, they could not enact the linguistic affordances offered by the scripted ingredients. Yet, unexpected affordances soon emerged, following the teachers' and students' temporary withdrawal from the simulation, also known as virtual corpsing (Marsh, 2003). However, virtual corpsing may potentially contribute to a loss of presence and to the emergence of chronotopes that not only interrupt the flow of the simulation but may also weaken the group cohesion and collaborative learning processes and outcomes.

Acknowledgements. We would like to thank Imparafacile Runo and all the people gravitating around Imparafacile Island for their priceless help in terms of work, time and enthusiasm. Also, we would like to acknowledge DIT for funding Ms Nocchi's attendance to the EuroCALL 2013 conference. 


\section{References}

Bakhtin, M. M. (1981). Forms of time and of the chronotope in the novel: Notes toward a historical poetics. In M. Holquist (Ed.), The Dialogic Imagination: Four Essays (pp. 84258). Austin: University of Texas Press.

Blin, F., Nocchi, S., \& Fowley, C. (2013). Mondes virtuels et apprentissage des langues : Vers un cadre théorique emergent. Recherches et applications, 54, 94-107.

Foucault, M. (1967). Of other spaces: Utopias and heterotopias. Retrieved from http://web.mit. edu/allanme/www/foucault1.pdf

Foucault, M. (1984). Dits et écrits, des espaces autres (conférence au Cercle d'études architecturales, 14 mars 1967). Architecture, Mouvement, Continuité, 5, 46-49.

Girvan, C., \& Savage, T. ( 2010). Identifying an appropriate pedagogy for virtual worlds: A Communal Constructivism case study. Computers \& Education, 55(1), 342-349. doi: 10.1016/j.compedu.2010.01.020

Kaptelinin, V., \& Nardi, B. (2012). Affordances in HCI: Toward a mediated action perspective. Proceedings of CHI 2012, New York (pp. 967-976). doi: 10.1145/2207676.2208541

Lemke, J. L. (2000). Across the scales of time: Artifacts, activities, and meanings in ecosocial systems. Mind, Culture, and Activity, 7(4), 273-290. doi: 10.1207/S15327884MCA0704_03

Ligorio, M. B., \& Ritella, G. (2010). The collaborative construction of chronotopes during computer-supported collaborative professional tasks. International Journal of ComputerSupported Collaborative Learning, 5(4), 433-452. doi: 10.1007/s11412-010-9094-4

Marsh, T. (2003). Staying there: an activity-based approach to narrative design and evaluation as an antidote to virtual corpsing. In G. Riva, F. Davide, \& W. A. IJsselsteijn (Eds.), Being There: Concepts, effects and measurement of user presence in synthetic environments (pp. 85-96). Amsterdam: Ios Press.

Morgan, M. (2007). Evaluating ICT in education using the concept of mediation. In S. Wheeler \& N. Whitton (Eds.), ALT-C 2007: Beyond control Learning technology for the social network generation, Research Proceedings, Nottingham (pp. 13-24). Retrieved from http://www.alt. ac.uk/altc2007/altc2007_documents/altc2007_research_proceedings.pdf

Riva, G. (2004). Psicologia dei nuovi media. Bologna: Il Mulino.

Riva, G., Waterworth, J. A., Waterworth, E. L., \& Mantovani, F. (2011). From intention to action: the role of presence. New Ideas in Psychology, 29(1), 24-37. doi: 10.1016/j. newideapsych.2009.11.002

Zheng, D. (2012). Caring in the dynamics of design and languaging: exploring second language learning in 3D virtual spaces. Language Sciences, 34(5), 543-558. doi: 10.1016/j. langsci.2012.03.010

Zheng, D., \& Newgarden, K. (2011). Rethinking language learning: Virtual World as a catalyst for change. International Journal of Learning and Media, 3(2), 13-36. doi: 10.1162/ ijlm_a_00067 